\title{
AN INTRINSIC SQUARE FUNCTION ON WEIGHTED HERZ SPACES WITH VARIABLE EXPONENT
}

\author{
MitsuO IZUKI AND TAKAHIRO NOI
}

Abstract. We define new generalized Herz spaces having weight and variable exponent, that is, weighted Herz spaces with variable exponent. We prove the boundedness of an intrinsic square function on those spaces under proper assumptions on each exponent and weight.

Mathematics subject classification (2010): 42B35. tion.

Keywords and phrases: Herz spaces, Muckenhoupt weight, variable exponent, intrinsic square func-

\section{REFERENCES}

[1] C. Bennett and R. Sharpley, Interpolation of Operators, Academic Press, Boston, San Diego, New York, 1988.

[2] D. Cruz-Uribe, A. Fiorenza and C. J. Neugebauer, The maximal function on variable $L^{p}$ spaces, Ann. Acad. Sci. Fenn. Math. 28 (2003), 223-238.

[3] D. Cruz-Uribe, A. Fiorenza and C. J. Neugebauer, Corrections to: "The maximal function on variable $L^{p}$ spaces", [Ann. Acad. Sci. Fenn. Math. 28 (2003), 223-238], Ann. Acad. Sci. Fenn. Math. 29 (2004), 247-249.

[4] D. CruZ-Uribe, A. Fiorenza And C. J. Neugebauer, Weighted norm inequalities for the maximal operator on variable Lebesgue spaces, J. Math. Anal. Appl. 394 (2012), 744-760.

[5] D. Cruz-Uribe, SFO, E. Hernández and J. M. Martell, Greedy bases in variable Lebesgue spaces, Monatsh. Math. 179 (2016), 355-378.

[6] D. CRUZ-URIBE AND L.-A. D. WANG, Extrapolation and weighted norm inequalities in the variable Lebesgue spaces, arXiv:1408.4499.

[7] L. Diening, Maximal function on generalized Lebesgue spaces $L^{p(\cdot)}$, Math. Inequal. Appl. 7 (2004), 245-253.

[8] L. Diening, Maximal function on Musielak-Orlicz spaces and generalized Lebesgue spaces, Bull. Sci. Math. 129 (2005), 657-700.

[9] L. DiENING AND P. HëstÖ, Muckenhoupt weights in variable exponent spaces, preprint, available at http://www.helsinki.fi/ hasto/pp/p75 _ submit.pdf.

[10] J. DuonndikoetXea, Fourier Analysis, Graduate Studies in Math. 29, Amer. Math. Soc., Providence, RI, 2001.

[11] M. FrAZIER AND B. JAWERTH, A discrete transform and decompositions of distribution spaces, J. Funct. Anal. 93 (1990), 34-170.

[12] V. Guliyev, M. Omarova AND Y. Sawano, Boundedness of intrinsic square functions and their commutators on generalized weighted Orlicz-Morrey spaces, Banach J. Math. Anal. 9 (2015), 44-62.

[13] M. IZUKI, Boundedness of sublinear operators on Herz spaces with variable exponent and application to wavelet characterization, Anal. Math. 36 (2010), 33-50.

[14] M. IZUKI, Remarks on Muckenhoupt weights with variable exponent, J. Anal. Appl. 11 (2013), $27-41$.

[15] M. IZUKI, E. NAKAI AND Y. SAWANO, Function spaces with variable exponents - an introduction, Sci. Math. Jpn. 77 (2014), 187-315.

[16] M. IZUKi, E. NAKAI AND Y. SAWANo, Wavelet characterization and modular inequalities for weighted Lebesgue spaces with variable exponent, Ann. Acad. Sci. Fenn. Math. 40 (2015), 551-571. 
[17] M. IZUKI, Y. SAWANO AND Y. Tsutsui, Variable Lebesgue norm estimates for BMO functions, II, Anal. Math. 40 (2014), 215-230.

[18] A. YU. Karlovich AND I. M. SPITKovsky, The Cauchy singular integral operator on weighted variable Lebesgue spaces, Concrete operators, spectral theory, operators in harmonic analysis and approximation, 275-291, Oper. Theory Adv. Appl., 236, Birkhäuser/Springer, Basel, 2014.

[19] H. KeMPKA AND J. VybíRAL, Spaces of variable smoothness and integrability: characterizations by local means and ball means of differences, J. Fourier Anal. Appl. 18 (2012), 852-891.

[20] O. KováčIK AND J. RÁKosník, On spaces $L^{p(x)}$ and $W^{k, p(x)}$, Czech. Math. J. 41 (116) (1991), 592-618.

[21] B. Muckenhoupt, Weighted norm inequalities for the Hardy maximal function, Trans. Amer. Math. Soc. 165 (1972), 207-226.

[22] J. L. Rubio De Francia, Factorization and extrapolation of weights, Bull. Amer. Math. Soc. (N.S.), 7 (1982), 393-395.

[23] J. L. Rubio DE FrAnCIA, A new technique in the theory of $A_{p}$ weights, Topics in modern harmonic analysis, Vol. I, II (Turin/Milan, 1982), 571-579, Ist. Naz. Alta Mat. Francesco Severi, Rome, 1983.

[24] J. L. Rubio De Francia, Factorization theory and A $p$ weights, Amer. J. Math. 106 (1984), 533-547.

[25] H. WANG, Intrinsic square functions on the weighted Morrey spaces, J. Math. Anal. Appl. 396 (2012), 302-314.

[26] H. WANG, Boundedness of intrinsic square functions on the weighted weak Hardy spaces, Integral Equations Operator Theory 75 (2013), 135-149.

[27] H. WANG, The boundedness of intrinsic square functions on the weighted Herz spaces, J. Funct Spaces 2014, Art. ID 274521, 14 pp.

[28] H. WANG AND H. P. LiU, Weak type estimates of intrinsic square functions on the weighted Hardy spaces, Arch. Math. 97 (2011), 49-59.

[29] M. WILSON, The intrinsic square function, Rev. Mat. Iberoam. 23 (2007), 771-791.

[30] M. WiLson, Weighted Littlewood-Paley theory and exponential-square integrability, Lecture Notes in Math., 1924. Springer, Berlin, 2008.

[31] X. WU, Commutators of intrinsic square functions on generalized Morrey spaces, J. Inequal. Appl. 2014, 2014:128. 